\title{
Die jungen Wilden kommen
}

Vorreiter zu sein, ist nicht immer ein Vorteil. Die Finanzbranche gehörte zu den ersten, die Informationstechnologie in großem Umfang eingesetzt haben. Das führte zur bekannten Legacy-Problematik - Altsystemen, die so geschäftskritisch sind, dass man sie kaum ersetzen kann. Gänzlich unbelastet von solchem Ballast sind vor etwa fünf Jahren "junge Wilde“ aufgetaucht - Startup-Unternehmen, die unter dem Schlagwort „Fintech“ innovative Lösungen anbieten, die eine neue - häufig kundenorientierte - Perspektive auf die klassischen Funktionen einer Bank oder einer Versicherung erlauben.

Fintech-Lösungen finden sich in allen Bereichen der bankbeziehungsweise versicherungsfachlichen Wertschöpfungskette - vom Zahlungsverkehr über Wertpapieranlagen hin zu Krediten und Absicherungsleistungen. Zu den Beispielen zählen Community-basierte Beratungsmodelle, Plattformen des Crowdfunding/-lending, Blockchain-basierte Bezahlverfahren oder Lösungen zur Anbindung neuer Endgeräte (Tablets, Smart Watches etc.).

Das Schwerpunktthema trägt mit mehreren Beiträgen zum Verständnis des Fintech-Phänomens und der damit verbundenen Geschäftsmodelle bei. Insgesamt acht Beiträge beleuchten die unterschiedlichen Facetten dieses Themas. In ihrem Einführungsbeitrag geben die Professoren Rainer Alt und Dieter Ehrenberg von der Universität Leipzig einen Überblick zu den im Heft enthaltenen Beiträgen - die beiden zeichnen zudem für die inhaltliche Gestaltung des Heftschwerpunktes verantwortlich.

Ich wünsche Ihnen eine anregende Lektüre

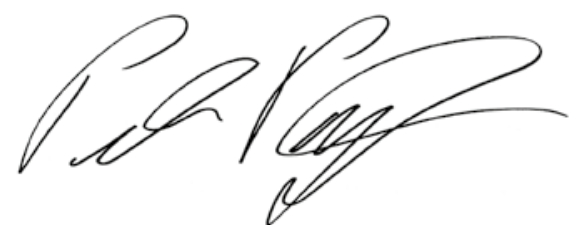

Peter Pagel, Chefredakteur

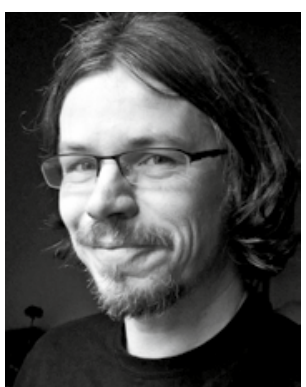

Peter Pagel

Chefredakteur 